\title{
LA ENTRADA EN EL MUNDO DE LA OBRA NARRATIVA AUDIOVISUAL A TRAVÉS DE TEMPS ET RÉCIT DE PAUL RICOEUR
}

\author{
Daniel Vela-Valldecabres ${ }^{1}$ : Universidad Complutense de Madrid. España \\ $\underline{\text { dvela@villanueva.edu }}$
}

\section{RESUMEN}

En el presente estudio, exponemos la experiencia docente en la asignatura Historia del cine, por la cual se analizan películas generacionales con el método de Paul Ricoeur. Para el análisis hemos tomado la Hermenéutica de Paul Ricoeur de textos narrativos en su libro Temps et récit, y aplicado sus conclusiones a textos audiovisuales. Ricoeur establece tres fases de análisis. La primera es la precomprensión de la obra o prefiguración, por la contextualización y explicación previa a la proyección de determinadas películas, estas se vuelven más asequibles para el espectador actual. La segunda fase, la configuración, sería el momento en que el espectador hace suya la película al verse reflejado o no en ella. Por último, la refiguración representa el momento de la recepción y aplicación en la vida real de los modelos que se ven en pantalla. El análisis de las películas generacionales y su impacto didáctico en la formación de los alumnos a través de la asignatura Historia del cine nos ayuda a valorar cómo los alumnos pueden conocer al mismo tiempo las características estructurales y formales de una generación y activar el pensamiento crítico hacia elementos que tienen que ver con la propia estructura de entendimiento de la realidad.

PALABRAS CLAVE: Cine - Didáctica - Juventud - Narración - Generacional

\footnotetext{
${ }^{1}$ Autor correspondiente

Daniel Vela-Valldecabres: Profesor Contratado Doctor del Centro Universitario Villanueva, adscrito a la Universidad Complutense de Madrid, España.

Correo: dvela@villanueva.edu
} 


\title{
PAUL RICOEUR TEMPS ET RÉCIT: THE AUDIOVISUAL WORLD OF NARRATIVITY
}

\begin{abstract}
The current study presents a teaching experience in the course "The history of films", in which youth films are analysed with the method of Paul Ricoeur. For this analysis we have followed the hermeneutics that Ricoeur applies to narrative texts -as discussed in his work Temps et récit- and we have applied them to audiovisual texts. Ricoeur distinguishes three stages of analysis. The first stage is pre-understanding of the work or prefiguration: by the contextualization and explanation previous to the watching of certain films, they become more accessible to the contemporary public. The second stage, configuration, is the moment when the viewer internalizes the film by seeing himself or herself reflected in the film or not. Finally, refiguration represents the moment when the models that have been seen on the screen are received and applied to real life. The analysis of youth films and their teaching impact in the education of students through the course "The history of films" can help us appreciate two aspects of the process. On the one hand, students can access, at the same time, both the structural and formal characteristics of a generation. On the other hand, critical thought is activated towards an understanding of elements which have to do with a global understanding of reality.
\end{abstract}

KEY WORDS: Cinema - Didactics - Youth - Narration - Generational

\section{INTRODUCCIÓN}

En el presente estudio se busca, en primer lugar, aplicar la hermenéutica de Paul Ricoeur a los análisis fílmicos y, en concreto, a tres películas: Sucedió una noche Rebelde sin causa y Cuatrocientos golpes. Ricoeur establece una metodología de análisis de textos narrativos, tanto históricos como literarios y aquí se presenta su aplicabilidad a la narrativa audiovisual. Este es el primer objetivo: establecer las bases para comprobar que es susceptible de aplicación.

Como segundo objetivo, se plantea que esta metodología de Ricoeur nos sirva para el aula, es decir, contrastar la posibilidad de que los alumnos puedan en una asignatura como Historia del cine profundizar más por medio de la entrada en el mundo de la obra. Se busca que en esta asignatura no solo se hable de directores, escuelas y actores cinematográficos, sino que además -con un fin educativo- se llegue a conseguir mejorar la forma de ser de los alumnos, que ven su vida reflejada en distintos films de la historia del cine. Para el presente trabajo se han hecho encuestas selectivas para conocer la opinión de los alumnos sobre las películas. 


\section{METODOLOGÍA}

\subsection{Metodología de Paul Ricoeur}

Paul Ricoeur, recientemente fallecido (en el 2005), es un filósofo francés que propone una interpretación de textos irenista, en su libro Temps et récit (1983-1985). Va extrayendo modelos del estructuralismo francés, de Heidegger, de Gadamer, de Iser y Jauss (estética de la recepción de la escuela de Constanza), etc.

Busca construir una hermenéutica de textos narrativos por los que comprenderse mejor como persona. Vamos a verlo detenidamente.

Antes de exponer resumidamente la teoría de Ricoeur sobre las tres mimesis, quiero aclarar algunos conceptos de Temps et récit, que además sirven de introducción a la hermenéutica que propone.

En Paul Ricoeur, la conformación de una trama ${ }^{2}$ por medio de la intriga, los fines, las causas y los azares en unidad de acción, es la que consigue dar el salto de entrada en un universo nuevo, el mundo de la obra (Ricoeur, 1983, p. 11). Es decir, el elemento esencial de toda narración es el entrelazamiento de acciones que se realiza a modo de "operación", por esto habla Ricoeur de "construcción de la trama", contando con los elementos tradicionales de ordenación de la narración: comienzo, desarrollo y desenlace (Ricoeur, 1983, p. 70 y 88-89).

Por otro lado, el concepto de mimesis aristotélico se entiende aquí como el de composición de acciones humanas -no como simple imitación de la realidad-, de manera que al verse proyectado, el lector siente liberar sus pasiones. Así, la actividad representadora (mimesis) y la estructura de las acciones (mythos) son conceptos intercambiables, equivalentes (Vela, 2005, p. 137).

Pues bien, para Ricoeur, es por medio de la narración como se puede entrar en el mundo de la obra, se entra en el juego de la ficción. Esta narración engloba la épica, la dramática y la historia (Ricoeur, 1984, p. 229-230) ${ }^{3}$. En el presente trabajo, tratamos de hacer ver que no solo en el discurso narrativo escrito se dan las condiciones para entrar en el mundo de la obra, sino que también en la narración audiovisual. La apertura al nuevo mundo consiste en la proposición de un mundo susceptible de ser habitado, más todavía si ese mundo no está acabado, si -como en las novelas contemporáneas y películas- el final queda abierto.

Al final, lo que propone Ricoeur es que el hombre pueda conocerse mejor por medio del discurso narrativo, para así poder actuar conforme a esa visión propia ajustada a

\footnotetext{
2 La "trama" es el mythos aristotélico, que sería la parte estructural del relato, es decir, la disposición
}

${ }^{3}$ Cfr. Ricoeur excluye del discurso narrativo la lírica, que entraría dentro de otro paradigma 
la naturaleza personal. La obra de arte se presentará así con el poder de descubrir y transformar el quehacer humano ${ }^{4}$.

Una vez aclarada la importancia de la trama en cualquier narración y ver también que esta trama es un concepto intercambiable con el de mimesis de Aristóteles; ahora exponemos muy resumidamente la teoría de las tres mimesis de Ricoeur.

Se trata de tres momentos en la interpretación de textos, por los que primero, "contextualizamos" la obra analizada (mimesis I); en segundo lugar (mimesis II), entramos en el mundo de la obra, en sus personajes, trama y evolución; y, tercero (mimesis III), recibimos el texto como espectadores que nos impacta o nos involucra en la obra para cambiar nuestro actuar.

\subsection{Mimesis I o prefiguración}

Mimesis I o prefiguración se podría definir como el marco común a creador y lector, por el que la acción narrada es capaz de ser inteligible, por medio del concepto de "pertenencia a" una cultura: una historia, entorno social, costumbres, etc. Este marco común se establece, por un lado, en la medida en que ya ha sido ordenada en otras narraciones. En definitiva, autor y lector mantienen un saber compartido, si bien el alcance de cada uno será distinto.

La ordenación en otras narraciones anteriores se construye con ayuda del tiempo y da lugar a una tradición de paradigmas. Así, cualquier obra singular se establece sobre un paradigma, sobre el que actúa como una innovación, y puede afectar al género, a los personajes, a la estructura, etc. De este modo, los paradigmas, nacidos a su vez de una innovación anterior, proporcionan reglas para la experimentación posterior en el campo narrativo.

El paradigma ha sido considerado como un paso previo, una precomprensión, por la que se es capaz de identificar una obra como perteneciente a un ámbito, según sus características.

Después del orden paradigmático, Ricoeur pasa ahora al orden sintagmático, para ello estudia la concepción estructuralista del relato por medio de cuatro autores:

\footnotetext{
${ }^{4}$ Esta parte, la explica Ricoeur a través de Heidegger, quien sostiene que ser hombre significa comprender. "La existencia del hombre no consiste en captar los datos del mundo de forma pasiva, sino que es un estar-en-el-mundo, no solo de modo físico, sino constituyendo él mismo el mundo. Y esta comprensión lleva consigo un compromiso, y ese compromiso se funda en su relación con los otros, es un estar-con-los-otros.

Para Ricoeur se derivarán una serie de consecuencias. La primera es que comprender no se dirige a la captación de un hecho, sino a la aprehensión de una posibilidad de ser. De esta noción, Ricoeur extrae una consecuencia metodológica para su análisis: comprender un texto no es encontrar un sentido inerte allí contenido, sino desplegar la posibilidad de ser, puesto que me comprendo siendo, estando. Y esta posibilidad se presenta por la lectura de la obra y la entrada en la intriga" (Vela, 2005, p. 143-144).
} 
Propp, Bremond, Greimas y R. Barthes. Con ellos se extraen los elementos compositivos constantes de todo relato.

Puesto que no tenemos espacio para presentar cada una de las estructuras de los relatos de estos autores, nos limitaremos a exponer brevemente el modelo simplificado de Greimas, tomado de su Sémantique structurale (Greimas, 1966, p. 263284 y 312-323), que parte de los modelos de Propp y Levi-Sratrauss. De las tereinta y una funciones de Propp, Greimas las reagrupa en veinte permitiendo así emplear un sistema básico: 1) Ruptura del orden y alienación; 2) Prueba principal; 3) Reintegración; y 4) Restauración del orden. En este modelo el personaje juega un papel decisivo en las reglas de composición narrativa.

En tercer y último lugar, en esta mimesis $I$, se exponen los recursos simbólicos que se consideran como procesos culturales que articula la experiencia. Estos símbolos son los que hacen que los agentes de la acción se muevan de una determinada manera, con arreglo a esas normas o frente a ellas y provocan que una acción sea mala o buena: tiene que ver con la ética de la acción según una cultura determinada (Ricoeur, 1983, p. 91-94). Es decir, todavía estamos en la mimesis I o prefiguración: aquel que interpreta una obra particular tiene unos presupuestos culturales donde se insertan los presupuestos simbólicos.

\subsection{Mimesis II o configuración}

El segundo movimiento o momento es la mimesis II o configuración, que corresponde a la mediación entre mimesis I y mimesis III y se realiza por tres formas de mediación:

a) partir de unos acontecimientos, se llega a la obra completa por la composición de factores heterogéneos;

b) relato.

Por el tiempo interno en el

De unos acontecimientos a la historia. La integración de acontecimientos en un todo que es la obra, se define como configuración. Sin embargo, dentro de esta unidad de la obra debe haber discordancias o conflictos: si la composición de la trama está bien trazada, del relato emerge un conflicto o punto de desequilibrio. Desde una cadencia de acontecimientos en una dirección, cambian o se reconducen por un momento de distorsión o discordancia. Y precisamente, el arte de componer consiste en mostrar concordante esa discordancia, que sea coherente.

Como explica Aristóteles en el análisis de la tragedia, al producirse la discordancia, no solo entra el juego racional de la coherencia en el cambio, sino que se añade un componente emocional al darse el temor o la compasión. Y estos sentimientos proporcionan un placer por liberar pasiones (la catarsis), que es el objeto perseguido por la composición: es un elemento imprescindible (Poética 53b, 12-13). 
Esta liberación de pasiones o catarsis puede producirse por los sentimientos de temor y compasión (que son los más propios de la tragedia griega), o la alegría ante el surgimiento del amor, o alivio por la solución de un conflicto, etc.: se trata de la creación de una disposición en el auditorio por una trama bien llevada y unos personajes verosímiles.

La acción se sucede por la suma de acontecimientos que solo tienen significado profundo al terminar la historia y mirarla en su totalidad. Por su capacidad de ser seguida, la historia proporciona la unidad, obtiene la concordancia en la discordancia y viene a su vez impregnada de tendencias o inclinaciones hacia el final.

Decía Ricoeur que la trama compone un conjunto de factores tan heterogéneos como son agentes, fines, medios, interacciones, circunstancias, resultados inesperados, etc.

Caracteres temporales. En la novela contemporánea se da preeminencia a los personajes en la narración y se sitúa el tratamiento del tiempo como eje en torno al cual se construye el relato. Mientras en la novela convencional existía un paradigma de sucesión cronológica con respecto al tiempo que facilita los análisis, en la nueva novela es difícil aplicar el concepto de mythos aristotélico precisamente por la falta de orden que se manifiesta en el rechazo de la cronología. Y esta falta de orden se presenta en su mayor radicalidad cuando desaparece el final y la novela queda abierta (Ricoeur, 1983, p. 53).

Al mismo tiempo, con los relatos cinematográficos actuales sucede lo mismo en gran medida, porque se producen saltos en la composición de la trama, siempre y cuando haya una coherencia y unidad en la historia.

Este carácter temporal del relato viene catalizado por el narrador, que es quien marca el punto de vista. Puede ser omnisciente y poseer una gran movilidad como ocurría en la novela del siglo XIX: la voz del narrador aparecía en solitario como voz primerísima, la cual iba dejando paso a las distintas voces de los personajes, de manera que se producía una alternancia entre los dos discursos: el narrador y los personajes. O bien puede ser un narrador-testigo o narrador-personaje, como sucede en textos más contemporáneos, con lo que se ven mermadas sus posibilidades de visión, pero por el contrario, es un narrador más "real", más acorde con la visión de una persona cualquiera.

También entra en el ámbito de los caracteres temporales la selección narrativa, es decir, los momentos que se escogen en una historia para contarlos. Y unida a la selección narrativa, se encuentra el tempo o ritmo interno con que se cuenta el relato.

\subsection{Mimesis III o refiguración}

Como último punto del análisis, Ricoeur habla de la Refiguración o mimesis III, momento en que el lector o espectador cobra protagonismo. El papel del receptor no 
consiste en intuir por la lectura o el visionado, sino en comprender mejor a través de la explicación de cómo se configura el texto (mimesis II).

Para este tercer y último momento, la mimesis III, seguimos a dos autores de la escuela de Constanza: Wolfgang Iser y Hans-Robert Jauss. El primero nos da la pista para hacer el trasvase de la configuración a la refiguración, que él aplica a la obra literaria y nosotros lo aplicamos a la obra narrativa audiovisual:

La obra literaria posee dos polos que podemos llamar polo artístico y polo estético, siendo el artístico el texto creado por el autor, y el estético la concreción realizada por el lector. De tal polaridad se sigue que la obra literaria no puede identificarse exclusivamente ni con el texto ni con su concreción. Puesto que la obra es más que el texto, ya que sólo adquiere vida en su concreción y esta no es independiente de las disposiciones aportadas por el lector, aun cuando tales disposiciones son activadas por los condicionamientos del texto. El lugar de la obra de arte es la convergencia de texto y lector (Iser,1979, p. 149)

Tanto la obra literaria como la obra narrativa audiovisual están concebidas para la recepción y de esto depende su interpretación. En esta recepción se dan cita tanto la prefiguración (mimesis I) como la configuración (mimesis II) ${ }^{5}$. Si un espectador tiene un gran bagaje audiovisual y cultural será capaz de entender mejor el texto presentado.

Estos dos autores a los que sigue Ricoeur (Iser y Jauss) marcan dos líneas de estudio diferentes dentro de la misma Escuela de Constanza. Por su parte, Iser sostiene que el texto individual "se actualiza [...] sólo mediante las actividades de una conciencia que lo recibe, de manera que la obra adquiere su auténtico carácter procesal sólo en el acto de su lectura [...]. La obra de arte es la constitución del texto en la conciencia del lector" (Iser, 1979, p. 149).

Iser habla también de la forma en que el receptor entra en el mundo de la obra. Con una primera lectura -o visionado- el receptor se hace una idea del texto y se deja impresionar y sorprender por la trama y los personajes. A partir de la segunda lectura o visionado, va descubriendo otros aspectos de la historia, siempre que la obra sea una gran obra:

La lectura discurre como una perspectiva móvil que liga entre sí las fases del texto. Si se realiza un curso temporal se recubrirá la segunda lectura haciendo surgir de ella elementos no dados en la primera lectura [...]. Una condición importante para ello es que no se repita en la segunda lectura el mismo modo de recorrido mediante el cual se realizó anteriormente una determinada configuración de sentido [...]. El modo de procesar la lectura evoluciona, puesto

\footnotetext{
${ }^{5}$ Decía Ricoeur: "El texto no llega a ser obra más que en la interacción entre texto y receptor" (Ricoeur, 1985, p. 117).
} 
que el recuerdo de lo leído no se extingue por completo, y suscita así la óptica para una nueva ordenación [...]. Por mínimas que sean las innovaciones, siempre ocurrirá que la configuración de cada proceso de lectura es estructuralmente irrepetible (Iser, 1979, p. 154)

El hecho de leer una obra clásica o de visualizar una gran obra audiovisual, actualiza el contenido del texto y da respuestas a interrogantes actuales. En esto consiste el secreto de los clásicos, en conectar con los intereses de los receptores de cualquier tiempo y lugar, por el uso de los universales. Se produce una fusión de horizontes del pasado con los del presente para dar la significación a la obra; estamos ante un diálogo intemporal: "toda obra no es solamente una respuesta que se ofrece a un interrogante anterior, sino a su vez una fuente de preguntas nuevas" (Ricoeur, 1985, p. 252).

El público se encargará de decidir qué obras son intempestivas y cuáles no. Sin embargo, nunca queda concluida la interpretación de textos, según Jauss, ya que mientras haya receptores nuevos, habrá nuevos modos de entender la obra de arte (Jauss, 1977, p. 244).

\section{ANÁLISIS Y DISCUSIÓN}

\subsection{Análisis de tres películas}

Una vez asentada la parte metodológica tomada de Ricoeur, el siguiente paso es el análisis de las tres películas por este método, con el fin de saber cómo los films influyen en las personas en general y en los alumnos en particular.

He escogido tres películas de temática juvenil de contrastado valor cinematográfico, que marcan puntos de giro en la historia del cine por ser innovadoras en sus argumentos o personajes. Son las siguientes: Sucedió una noche de Frank Capra; Rebelde sin causa, de Nicholas Ray; y en tercer lugar, Cuatrocientos golpes, de Truffaut.

\subsection{Sucedió una noche ("It happened one night". 1934)}

Sucedió una noche (1934), es la obra iniciática de las screwball comedy de EE.UU. Para entender este film hay que situarse en el contexto histórico del comienzo del New Deal ("nuevo trato") de Roosevelt, que fue elegido presidente de EE. UU. en marzo de 1933. El conocido como New Deal consiste en la intención institucional de resurgir del Crack del 29. Para esto, una de las medidas iba dirigida a elevar los ánimos de los ciudadanos desfavorecidos por medio de la realización y proyección de películas con fuerte carga esperanzadora y de superación. Para ello, se alió el gobierno con directores y productores de Hollywood.

Como subgénero emblemático de este espíritu, surge la screwball comedy que tiene como punto de arranque la película de Capra Sucedió una noche (Echart, 2005, p. 144). 
Al tratarse de la primera de un sinfín de películas de este género, hace que no tenga un paradigma claro anterior en donde basarse para la historia.

En cuanto al objetivo o mensaje que pretende transmitir es el del efecto estabilizador en la sociedad estadounidense, contribuyendo a la reformulación de la identidad nacional. Y la mejor forma para conseguirlo fue la propagación de mensajes positivos con el inevitable corolario del happy end (Echart, 2005, p. 32-43)

Si analizamos ahora la composición de la obra, vemos que están integradas las acciones hacia el final feliz. Ellie (Claudette Colbert) va a casarse con un piloto solo por el despecho de abandonar la casa paterna donde se ve encorsetada. Pero el conflicto surge durante el viaje de huida de su padre para encontrarse con el piloto, y es cuando conoce a Peter (Clark Gable) con quien va surgiendo el amor poco a poco a lo largo del trayecto. Ella, con su primer compromiso solo buscaba el escapismo, pero Peter le hace comprender que el amor es algo distinto: compartir lo cotidiano, comprenderse, etc. Así se da paso a un final made in Hollywood, de boda in extremis. Con la complementariedad de los caracteres se va fraguando la catarsis final, al experimentar el espectador la satisfacción de encontrar el amor verdadero, sin que Ellie tenga que abandonar a la propia familia.

La estructura de la narración es absolutamente clásica, porque de la situación inicial se pasa a la ruptura del orden establecido por la fuga de la hija del magnate, con su consiguiente conflicto; posteriormente, la "prueba principal" que consiste en el viaje iniciático de la protagonista hacia Nueva York en autobús y la superación de la prueba con la ayuda de Peter, para terminar con una reintegración del orden roto, con el encuentro del nuevo amor y restauración del orden por el matrimonio final con el periodista.

En cuanto a los temas tratados, destacan el amor, las diferencias sociales, la juventud rebelde y la mujer liberada entre otros; pero en todos los casos en torno a la pareja que va conociéndose a lo largo del viaje. Peter y Ellie experimentan la "batalla de sexos", es decir, el tira y afloja de conveniencias particulares y puntos de vista distintos en el trato, que hace que poco a poco vayan comprendiéndose mutuamente y apreciándose. Como se decía en La fiera de mi niña, otra de las grandes screwball comedy: "El impulso amoroso se expresa muy frecuentemente en el hombre en forma de conflicto". Las riñas en la pareja juegan un papel de distancia a veces y de profunda confianza e intimidad otras. Por encima de enfrentamientos, se muestra que están hechos el uno para el otro.

Además, la diferencia social parecía marcar una distancia insalvable entre ellos, pues ella proviene de una familia acaudalada y él es un simple periodista de calle. Sin embargo, en la evolución de los personajes, se va produciendo por el trato un refinamiento de las costumbres de él y, sobre todo, una reeducación de ella, de manera que comienza a interesarse por los problemas de las personas en dificultades. Esta superación del antagonismo en la pareja recuerda a los espectadores estadounidenses de la Depresión que el amor y la bondad son independientes de los 
estratos sociales, y que cabe mantener la fe en el ideal americano de una utópica sociedad sin clases.

Ellie es una mujer liberada, comparable a las famosas flapper, aquella "nueva mujer" de los felices veinte en EE. UU., la joven de la Edad del Jazz que protagoniza una revolución en la moda y en las costumbres. Si bien en el crack de octubre del 29 desaparecieron de un plumazo este prototipo de mujer moderna, también es cierto que sus costumbres y victorias sociales se mantuvieron en las screwball comedy como ocurre en Sucedió una noche. Ellie se trata de tú a tú con Peter: se establece una relación igualitaria en autonomía y libertad, en la que se produce una complementariedad. Queda atrás la concepción victoriana de la pareja.

Peter, por su parte, es al principio de la historia un cínico periodista, muy al uso de los protagonistas de las películas de los años veinte en Hollywood. Sin embargo, conforme avanza la trama va ganando en humanidad y se descubre al romántico que lleva dentro. Al principio del film, Peter usa sus tretas para conseguir exclusivas en el periódico y su ingenio de palabra para obtener confort; pero más adelante en el trato con Ellie, va perdiendo cinismo y creciendo en amabilidad, mientras sigue usando sus tretas para ayudarla a ella o para afianzar su relación, además de empezar a mostrar compasión y comprensión hacia las personas del pueblo llano.

Como vemos, quedan atrás los personajes amargados y fuera de la ley: los gansters, las mujeres caídas -madres solteras, amantes y prostitutas-, los corruptos policías y políticos, así como los convictos. En estos personajes se muestra el triunfo de lo cotidiano, tanto por los ricos diálogos de una pareja en el día a día, como por la temática que muestra: al final, es el enamoramiento de una pareja en un viaje.

Por otro lado, el narrador es el tradicional omnisciente, pues se van alternando secuencias de la huida en el autobús con las de los agentes contratados por el padre de ella. Nos va llevando hacia lo que le interesa para crearnos una situación de resolución airosa en el final de la película.

Es una película que gusta prácticamente por unanimidad a los alumnos encuestados. La ven moderna, a pesar de ser de 1934, con problemas que consideran actuales, tales como: la diferencia de clases, el sentido del humor, el amor que surge "por casualidad" y el final feliz que lleva a terminar con "buen sabor de boca".

Coinciden varias de las alumnas en que se sienten identificadas en la actitud de la protagonista de querer escapar de todo, y de la familia en concreto, para vivir su vida. Aparte, ellas son las que más encuentran en el amor entre los protagonistas un valor en la película: que surge en cualquier situación y que mantiene hasta la conclusión la incógnita de si será definitivo. Algunos alumnos varones, por su parte, se ven identificados con Peter en quien valoran su "desparpajo" o "chulería", además de su humanidad y comprensión. 
Por otra parte, han coincidido varios en destacar que el conocimiento previo a visionar la película, sobre la situación del New Deal en EE.UU. les ha llevado a entenderla mejor.

\subsection{Rebelde sin causa ("Rebel without cause". 1955)}

Los años cincuenta en EE.UU. son de prosperidad económica, impulsados por la mentalidad optimista de una sociedad recién salida de una gran victoria bélica. Sin embargo, la industria de Hollywood se encontraba con un déficit de imaginación. Las historias de guerra estaban agotadas y los tiempos que corrían eran de duro trabajo, realistas. Influidos por el neorrealismo europeo, los realizadores norteamericanos salieron a la calle en busca de historias más duras, de mayor crudeza social. A partir de aquí, temas como la corrupción, el alcohol, las drogas, el racismo o la codicia entrarán inevitablemente y hasta nuestros días en las películas sobre la juventud en las pantallas de cine. Además, este tipo de producciones fueron las responsables del nacimiento de un nuevo tipo de personaje cinematográfico con gran protagonismo sociológico durante toda la década y en momentos posteriores: el joven rebelde y conflictivo que detesta el sistema de vida que han creado los mayores. Sin lugar a dudas, quien mejor encarnó este prototipo de juventud fue James Dean, personaje indolente, y orgullosamente distante que causó una auténtica conmoción social tras protagonizar cintas como Al este del Endén y Rebeldes sin causa.

En esta última película de Nicholas Ray, se refleja una nueva problemática social: la juventud que rechaza la autoridad de los progenitores. Unos padres hechos a sí mismos, distintos y distantes de los jóvenes, que no congenian con sus hijos, porque tienen otros intereses imposibles de conjugar y de comunicar a sus hijos y viceversa.

La integración de las acciones en Rebelde sin causa está bien construida porque los problemas de Jim (James Dean), el protagonista, con sus padres, y los de Judy (Natalie Wood) con los suyos son desde el comienzo de ordinaria administración. Es decir, las familias de él y de ella no están desestructuradas, sino que tienen los roces normales de unos padres con sus hijos adolescentes, pero en el fondo se mantiene unida la familia como núcleo estabilizador. El caso de Jim es el del hijo que no puede verse reflejado en su padre, el cual es apocado e inseguro al que de una manera clara Jim desprecia una y otra vez. El chico comenta al principio en la comisaría a un policía: "Mi madre hace lo que quiere de él (su padre), y él se resigna. Ella le convierte en nada; a mí no me gustaría llegar a ser como mi padre. Quiere hacerse amigo mío, pero ¿cómo voy a fiarme de él? Si alguna vez, aunque sea por un día, no me diera vergüenza de él, entonces, a lo mejor...".

Por su parte, Judy tiene un padre que la considera una "perdida" por su comportamiento superficial y un tanto díscolo e informal. En una escena se muestra cómo el padre le da una bofetada a su hija porque ella intenta darle un beso de despedida 
El caso de Platón, un amigo de Jim, es distinto, porque sí se ve en él la imposibilidad de un sustento familiar. Sus problemas son de mayor calado que llegan a la desesperación. "No tiene a nadie en este mundo que le quiera", como dice su cuidadora lacónicamente, y termina muriendo. Cuando sucede este hecho, Jim y Judy ven que ellos sí tienen a su familia detrás que les comprenden o al menos, lo intentan. Por tanto, vemos una coherencia interna en el desenlace de la trama a través de los personajes.

Aquí la estructura sigue siendo clásica, porque se produce una ruptura del orden establecido al enfrentarse Jim con la pandilla de Buzz, que corresponde al conflicto; a continuación, la prueba principal se identifica con el objetivo común de Jim y Judy de salvar a Platón; y la conclusión viene dada con la restauración del orden de las dos familias centrales de él y ella al sentirse de nuevo unidas tras la muerte de Platón. La catarsis se produce porque surge el amor entre ambos jóvenes, también por la compasión por Platón por su situación familiar y su final trágico; y por el sentimiento de alivio al terminar reconciliadas las dos familias con sus hijos Ellie y Jim.

El tema del amor entre la pareja de jóvenes incomprendidos surge en gran medida por una búsqueda de refugio común y de escapatoria del ámbito familiar. No tienen el planteamiento de un noviazgo "formal", al uso, sino de comprensión y de mutuo reconocimiento frente a una autoridad paterna corrompida e inoperante. Quieren crear un espacio al margen de la mentalidad adulta oprimente y todo ello, no cabe duda, tendrá una gran repercusión en la estructura de la sociedad donde viven.

Además del amor, aparece el tema de las riñas y bandas juveniles, ya que Jim lucha con navaja contra Buzz, el jefe de una banda del instituto. Y no solo esto, sino que se retan en una "carrera" sui generis de coches en la que termina muriendo Buzz.

El narrador es omnisciente: se alternan las secuencias de manera tradicional, según la conveniencia de la historia para concluir con la trágica escena final, en el observatorio, donde muere Platón.

La valoración de la recepción de esta película ha sido desigual: a un $40 \%$ les ha gustado mucho o bastante, pero a otro $30 \%$ no les ha gustado en absoluto; sin embargo, estos últimos apuntan que reconocen su valía, como un clásico que hay que ver, por la profundidad de los temas que trata, por los originales personajes y el guión.

Tanto los alumnos como las alumnas se ven reflejados en las disputas entre padres e hijos, en las que no solo tienen culpa los hijos. Los alumnos, en casos, se ven identificados con la manera de ser de Jim (James Dean), porque se ven mezclados en problemas que no saben cómo afrontar o, simplemente, por ser un personaje con carácter fuerte que no se deja manejar por otros fácilmente. También destacan la actualidad del film en algunos aspectos tales como el orgullo como fuente de problemas familiares y entre amigos, la dificultad en la integración social, etc. 


\subsection{Los 400 golpes ("Les quatre cents coups". 1959)}

Esta película de François Truffaut es emblemática del movimiento francés NovelleVague o Nueva Ola. Es un movimiento que surge a finales de los cincuenta, cuando el 75\% del público cinematográfico tenía menos de 25 años. Y, sin embargo, seguía haciéndose el cine envarado, académico y literario. Algo que resultaba particularmente cierto en Francia y que quedaba muy en evidencia tras el neorrealismo italiano.

La Nouvelle Vague representa una ruptura con el cine académico francés de los años cincuenta, con el lanzamiento de películas de bajo presupuesto: un cine joven, con directores jóvenes, para un país joven. Todo ello asentado en la noción del director como autor, impensable en el Sistema de Hollywood (cine de productor) y excepcional antes del neorrealismo. François Truffaut fue uno de los jóvenes realizadores que provienen de la crítica de la revista Cahiers du Cinéma, y que realiza la autobiográfica Los 400 golpes: tierno retrato de una infancia baqueteada por la dureza del entorno. Es una película autobiográfica: igual que el protagonista, Truffaut no conoce a su verdadero padre, nunca fue un alumno ejemplar, si bien era un lector apasionado; también hacía novillos para ir al cine, además de ir a parar a un correccional por pequeños hurtos.

La estructura del film no corresponde exactamente a la composición narrativa tradicional:

a)

Tenemos una situación inicial de comienzo de conflicto en la familia de Antoine (Jean Pierre Leaud), el protagonista; porque el ambiente es muy tenso con sus padres: el padrastro le pega por sus travesuras en el colegio y en casa, la madre no le quiere, en el colegio es maltratado... en definitiva, así se fragua la ruptura del orden y alienación".

b)

La "prueba principal" consiste en su supervivencia en las calles de París y posteriormente en el correccional adonde le mandan sus padres.

c)

Se "reintegra al orden" al escapar del correccional, porque él estaba ansioso por la libertad; pero queda el final abierto porque no existe una restauración del orden externo como suele pasar en la estructura tradicional de los relatos. Como ya comentamos, el final abierto es propio de las historias contemporáneas (desde mitad de siglo $\mathrm{XX}$ ) y refleja un realismo que se hermana con los "narradores protagonistas", como es el caso

Se puede apreciar la "integración de las acciones" en esta película, ya que la gradación en una espiral de desgracias que le suceden a Antoine, es coherente: tanto porque su situación familiar no es favorable, como su tendencia a las travesuras en el colegio (aunque él no sea mal chico), incluso su pequeña dosis de mala suerte. Todo lleva a desembocar en el correccional. 
La catarsis viene dada por la compasión que produce el chico al ver las desgracias a las que se ve abocado; y principalmente, el momento cumbre que toca la fibra sensible es cuando llora porque le trasladan en un furgón enrejado hacia el correccional, dejando atrás su familia, sus amigos, el colegio y, sobre todo, la libertad. Al final de la película surge otro sentimiento de recuperación de la libertad perdida al escaparse del internado y llegar a la playa.

El narrador de este relato audiovisual es en tramos narrador-protagonista, en tramos narrador omnisciente. Aunque no haya voz en off suya, ni cámara subjetiva, sí va siguiendo la cámara al chico de manera que prácticamente solo sabemos lo que sabe él, si bien encontramos el narrador omnisciente en algunos tramos. Al final de la película es cuando se muestra más claramente la subjetividad de la información, en el momento en que queda encerrado por las paredes del internado; entonces es cuando ya no sabemos nada de la escuela, ni de la familia, ni de los amigos; más que cuando van a verle al internado.

Sobre la recepción de la película, destaca que ha sido el film con más extremos en su valoración: a algunos les encanta y a otros les aburre, sin diferencia de sexos. Coinciden en que es una película muy psicológica, subjetiva, y que les ayudó a saber que era autobiográfica -por parte de Truffaut- para entenderla mejor. Destacan su modernidad por los temas sociales tratados, el realismo de los personajes, la labor del director de actores y el final abierto. También es cierto que por su realismo reconocen la distancia que les separa de tiempo con la sociedad que se refleja en el film

Algunos pocos chicos, se ven identificados con el protagonista, por el ambiente en el colegio, por su trato con los compañeros, si bien la escuela que se presenta es antigua en estilo. Aparte, la mayoría sienten compasión y comprensión hacia Antoine y angustia al verle en el reformatorio, junto con el alivio final, con sabor agridulce al no saber cómo seguiría la historia del protagonista.

\section{CONCLUSIONES}

El primer objetivo perseguido fue el de la aplicabilidad de la hermenéutica de Ricoeur a los relatos audiovisuales. Como hemos hecho ver en los análisis de las tres películas, ha quedado demostrado que son perfectamente intercambiables las categorías que Ricoeur aplica a los textos literarios e históricos a los textos audiovisuales. También es cierto que no hemos podido demostrarlo en todos los puntos propuestos en la "metodología de Ricoeur" por falta de espacio, sin embargo, esto ha de tomarse como una primera aproximación al trasvase texto-imagen que continuará en posteriores trabajos.

En segundo lugar, con la recepción de las películas por parte de los alumnos también se ha podido demostrar que los alumnos de Historia del cine han conseguido profundizar de tal manera en las películas que les han hecho identificarse con 
personajes y situaciones. Queda como segundo paso y definitivo, objeto de estudios posteriores, saber si esta implicación en los films les ha llevado a replantearse su propia forma de ser e incluso cambiar a mejor como persona.

\section{REFERENCIAS}

Echart, P. (2005). La comedia romántica del Hollywood de los años 30 y 40. Madrid: Cátedra.

GreimaS, A. J. (1966). Semantique structurale. Paris: Larousse.

Iser, W. (1979). El proceso de lectura», en Warning, R. (ed.). Estética de la recepción. Madrid: Visor.

Jauss, H.-R. (1977). Experiencia estética y hermenéutica literaria. Madrid: Taurus.,

Ricoeur, P. (1983). Temps et récit I. Paris: Seuil.

Ricoeur, P. (1984) Temps et récit II. Paris: Seuil..

Ricoeur, P. (1985) Temps et récit III. Paris: Seuil.

Vela Valldecabres, D.1 (2005). Del simbolismo a la Hermenéutica: Paul Ricoeur (19501985). Madrid: CSIC.

\section{Daniel Vela-Valldecabres}

Licenciado en Filología Hispánica por la Universidad Complutense de Madrid. Doctor en Filología Hispánica por la Universidad de Navarra. Es profesor Contratado Doctor en el Centro Universitario Villanueva. Tiene varios libros publicados: en el ámbito de la Teoría de la Literatura. Ha trabajado en diversas líneas de investigación como la recepción del mensaje periodístico y publicitario; la Generación X y el cine; la seducción del mal en el cine actual. Además, ha participado como miembro en cuatro proyectos de investigación. 